\title{
Insurance Regulation and the Global Financial Crisis: A Problem of Low Probability Events*
}

\section{Christopher O’Brien}

Business School: Centre for Risk and Insurance Studies, Nottingham University Business School, Jubilee Campus, Wollaton Road, Nottingham, Nottinghamshire, NG8 1BB, UK.

E-mail: christopher.obrien@nottingham.ac.uk

We consider probabilistic approaches and stress tests as methods for regulators to set the minimum solvency margin for insurers. Each method has advantages and disadvantages. We assess the implications of the global financial crisis for each method, concentrating on life insurers. We have concerns that the probabilities used in probabilistic approaches are not robust. Regulators may find it beneficial to focus on the use of stress tests, although there are lessons to learn from the global financial crisis about the design and use of such tests.

The Geneva Papers (2010) 35, 35-52. doi:10.1057/gpp.2009.36

Keywords: insurance regulation; internal models; probabilistic modelling; scenario testing; Solvency II; stress tests

\section{Introduction}

The global financial crisis has led to a major rethink of banking regulation, with the authorities reviewing the approaches they use to set minimum capital requirements for banks. In particular, regulators have raised concerns about the probabilistic modelling that banks use, where they use models that project alternative outcomes and the probabilities of each. However, regulators have also reported problems with the use of stress tests, which is where regulators define a set of scenarios and the required capital that is needed to ensure solvency in the most demanding scenario.

Insurers have also been caught up in the crisis, evidenced by the U.S. bailout of American International Group (AIG) and, in Europe, the weakening of the financial position of many insurers and reinsurers. The contribution of this paper is to review the merits and problems of, and the roles that can be played by, probabilistic modelling and stress tests in the regulation of insurers. We favour an increased emphasis on stress tests, where we suggest some new ideas to supplement others that have already been put forward. We concentrate on the position of life insurers, whose

\footnotetext{
* The author would like to thank Stephen Diacon, Kevin Dowd and Margaret Woods for helpful comments, and also to participants at the 2009 conference of the European Risk Research Network. He also acknowledges helpful comments from two anonymous referees. Remaining errors are, of course, the author's responsibility.
} 
substantial investment portfolios have led to their being especially exposed during the crisis, and focus on the U.K., using evidence from life insurers' probabilistic modelling and stress testing.

It is hoped that the paper will be of interest to both insurers and regulators as they grapple with the challenges of maintaining solvency, knowing that situations as arose in 2008, which would have been regarded as highly improbable can, in fact, happen. European insurance regulators have already been considering the implications of the crisis for Solvency II, planned for implementation in the European Union in 2012 .

The paper continues by describing the various approaches to setting insurance solvency requirements, and goes on to consider stress tests and probabilistic approaches in more detail. We then review the impact of the global financial crisis on stress tests and probabilistic approaches, identify gaps in probabilistic modelling and suggest three lessons for regulators.

\section{Approaches to solvency regulation}

We can set out four main ways to determine minimum solvency requirements based on a report by KPMG for the European Commission: ${ }^{1}$ fixed ratios, risk-based capital, scenario methods and probabilistic approaches.

The fixed ratios method is a formulaic approach using one or more fixed proportions as a proxy for an insurer's exposure to risk. The European Union's Solvency I rules are basically a fixed ratios regime.

Risk-based capital aims to set a minimum solvency requirement that reflects the size and overall risk exposures of an insurer. While this is similar to fixed ratio approaches, it uses more risk proxies and factors than a fixed ratio approach and is more refined. This approach is exemplified by the solvency rules in the United States.

Scenario approaches analyse the effect of specific risk variables (for example, claim rates or interest rates) on company-specific exposure, with the minimum solvency requirement calculated as the capital needed to ensure that even in the worst-case outcome from a set of scenarios, the insurer will still have assets equal to liabilities. If only one risk variable changes, this is sometimes referred to as a "stress test". 2 Alternatively, "stress test" can be used (as we shall use it) to cover changes in several variables, that is synonymous with the scenario approach, addressing the question, what capital is needed to ensure that the insurer can cope with changed conditions?

KPMG describe probabilistic modelling approaches as attempting to cover the full range of risk variables that are sampled from a statistical distribution in a simulation procedure. The results not only consist of outcomes related to specific scenarios, but also take account of the probability of those outcomes. Stochastic modelling is one example of statistical techniques to produce this. We will refer to the probabilistic approach in this paper as one where the minimum solvency margin is set using the

\footnotetext{
${ }^{1}$ KPMG (2002). Subsequent references to KPMG in this paper are to this work.

${ }^{2}$ Association of British Insurers (2007).
} 
probabilities of one or more outcomes. This is distinct from the use of stress tests, in which the scenarios are set out, but where the probability of a scenario arising is not specified as such (although regulators will implicitly have in mind that the probability of the scenario is low).

The fixed ratios approach now appears unsophisticated, certainly failing to give suitable incentives for insurers to manage risks appropriately. While the International Association of Insurance Supervisors (IAIS) found that using fixed ratios is still common, there is evidence of more advanced approaches in place. ${ }^{3}$ While risk-based capital is an improvement on fixed ratios, regulators have set their sights higher. This paper therefore concentrates on stress tests and probabilistic approaches.

\section{Probabilistic modelling and stress tests outside insurance}

Risk encompasses both the idea of some probability of a future event and, if that event occurs, the effect of the event, which may be offset by actions a firm can take over a period of time. There is no unique best way to measure the risks to which a firm is exposed. Financial risks are more amenable to measurement than non-financial risks, and banks and insurers, being especially concerned with financial risk, have been at the forefront of developing risk measures. In the late 1970s, banks began developing models to produce Value at Risk ( VaR), that is what loss was not expected to be exceeded over the next trading day, with some specified probability level (e.g., 99 per cent) and holding period, that is the time before the portfolio could be rearranged (e.g., 5 days). ${ }^{4}$ The use by banks of VaR is now widespread. Probabilistic modelling can also produce "Tail Value at Risk" (TVaR), which is the average loss of the losses above the specified probability level.

Banking regulators have also wished to see banks disclose risk measures, and the Fisher report in $1994^{5}$ suggested VaR as one way of disclosing market risks. The Basel capital accord was amended in 1996 to introduce market risk-related capital requirements, calculated either on a standard basis or using the bank's internal model. Use of a model was subject to approval from the regulator, with a number of conditions. For example, the bank's model had to have a proven track record of reasonable accuracy in measuring risk. VaR has a number of merits as a risk measure, measuring risks consistently across different financial assets and liabilities, taking into account correlations between risks and the hedges that a firm has in place.

To use an internal model, a bank also had to have in place a rigorous and comprehensive stress testing programme. Stress scenarios "need to cover a range of factors that can create extraordinary losses or gains in trading positions, or make the control of risk in those scenarios very difficult". ${ }^{6}$

\footnotetext{
${ }^{3}$ IAIS (2009).

${ }^{4}$ Woods et al. (2008).

${ }^{5}$ Bank for International Settlement (1994).

${ }^{6}$ The provisions of the Basle Committee on Banking Supervision (1996) are summarised in this paragraph.
} 
Accounting standard-setters have also set requirements for firms to disclose the risks to which they are exposed. In the U.S., Financial Reporting Release (FRR) $n^{\circ} 48$ in 1997 required firms to disclose market risk information for risk of loss arising from adverse changes in interest rates, foreign currency rates, commodity prices and equity prices. The disclosure could take one of three forms: briefly, tabular disclosure of cash flows (so that readers could assess the exposure to market changes), sensitivity tests and VaR. The sensitivity tests were similar to stress tests, but not intended to be extreme scenarios: it was envisaged that firms use changes that were not less than 10 per cent of end-of-period market rates or prices. ${ }^{7}$ One advantage for investors of sensitivity analysis is that they reveal not only the magnitude, but also the direction of the exposure, that is whether a change in interest rates is favourable or not. ${ }^{8}$ Most firms reporting using FRR $n^{\circ} 48$ used sensitivity analysis rather than tabular presentation or VaR.

Other accounting standards have been introduced, requiring disclosure of risk exposures. When the International Accounting Standards Board (IASB) issued International Financial Reporting Standard (IFRS) 4 (Insurance contracts) in 2004 it required insurers to disclose the sensitivity of profit or loss and equity to changes in variables that had a material effect on them. IFRS 7 (Financial instruments: disclosure), applicable more generally, requires a sensitivity analysis of how profit or loss would have been affected by changes in relevant market risk variables, or an analysis such as VaR. Banks, meanwhile, have to face Basel II, where the third Pillar (market discipline) requires banks to disclose $\mathrm{VaR}$ data if they use the internal models approach for the trading portfolio in assessing the amount of capital that is required.

However, probabilistic modelling has been subject to criticism. Some of the concerns are about $\mathrm{VaR}$ as a measure of risk. ${ }^{9}$ It is not a coherent risk measure, because it is not sub-additive: if we merge two portfolios, we ought to expect that the risk of the combined portfolio is no greater than the sum of the risks in individual portfolios-however, VaR can give the reverse result. It considers only one risk level (e.g. the $99^{\text {th }}$ percentile) and ignores the higher risk levels in the tail. An alternative is TVaR, which is a coherent risk measure. A firm using this also has the advantage of having to assess possible extreme losses, which can stimulate thought on how to manage them. Doff ${ }^{10}$ notes that TVaR is theoretically more correct than VaR but accepts that VaR has some practical advantages.

There are several other issues about the probabilistic approach. ${ }^{11}$ Some banks base their calculations on historical data on their past losses, which may or may not be a good guide for the future. This also raises the question as to how much past data are used: some banks use only one year's results. They convert that past data into a probability distribution, commonly using the normal distribution, which ignores the plentiful evidence of fat tails in such distributions. Other banks use Monte Carlo simulation, which raises the issue of how robust the assumptions in the probability distribution are.

\footnotetext{
${ }^{7}$ Linsmeier and Pearson (1997).

${ }^{8}$ Linsmeier and Pearson (1997).

${ }^{9}$ See, for example, Dowd and Blake (2006).

${ }^{10}$ Doff (2008).

${ }^{11}$ See Woods et al. (2008).
} 
More generally, authors have questioned whether it is reasonable to think that we can derive probabilities from models in a way that is robust. A notable critic is Taleb, who discusses "Black Swans", highly improbable events with massive impact such as 9/11. ${ }^{12}$ A practising risk manager, Rebonato, ${ }^{13}$ views the use of quantitative precision as excessive and misleading. VaR has, however, retained its appeal to banks (and their regulators) and some non-financial companies, but with stress testing also playing an important role, especially for risks where $\mathrm{VaR}$ is felt to be inadequate, for example where the risks related to emerging markets, where markets are less liquid and the data are lacking. ${ }^{14}$

\section{Stress tests in insurance}

Stress tests demonstrate the impact on a firm's finances of a stress, such as a 25 per cent reduction in share prices, enabling the firm to decide if it is a serious problem and hence needs further risk management action. The test does not say how likely the 25 per cent fall in share prices is. A stress test is essentially a sensitivity test but at a more extreme level.

KPMG saw the advantages of stress tests as the following:

- They allow for a straightforward and intuitive interpretation of results, with capital requirements being clearly defined.

- Scenarios provide flexibility in the scope of risks considered.

- There is a clear and flexible framework for considering risk interactions, with recognition of reinsurance and hedges.

- Models can be dynamic and forward looking, and provide a suitable tool for internal risk management.

However, they also listed some disadvantages:

- The definition of capital depends on the scenario test, hence hinges critically on the completeness and relevance of the scenarios used, with the result possibly being arbitrary.

- The more sophisticated versions have considerable data requirements, and may require complex modelling, with resulting high costs.

- The potential for subjectivity can make comparability difficult.

The U.K. insurance regulator introduced a form of stress test for life insurers in 1985, referred to as a "resilience test". This required firms to calculate the additional capital that would be required to maintain their solvency position in the event of a 3 percentage point rise or fall in interest rates and a 25 per cent change in the value of equities and property. The outcome was not regarded as a capital requirement; instead, the figure was added as part of the insurer's liabilities. However, some calculations suggested that 3 per cent/25 per cent might be too strong in some circumstances, but

\footnotetext{
12 Taleb (2007).

13 Rebonato (2007).

${ }^{14}$ Fender and Gibson (2001).
} 
not so in others. ${ }^{15}$ The precise form of the test was altered in later years, sometimes as a result of changes in financial conditions that occurred, which may be interpreted as a sign that devising an appropriate and objective stress test is difficult, or a sign that stress tests have the flexibility to cope with changed circumstances.

These stress tests were straightforward to implement. However, other stress tests can be more complex, and only practicable if an insurer has a model of its business that can be used to assess, approximately, the financial position of the insurer in the alternative scenario.

In 2004, the FSA introduced two new requirements for major life insurers writing participating business. ${ }^{16}$ Firstly, it required them to report the market-consistent ("realistic") value of their assets and liabilities. This included valuing the options and guarantees in their products, and as market prices for these were not directly observable - the options are much longer term than options traded on financial markets - they needed to have a financial model of their business in order to complete this "realistic valuation".

This new modelling involved some significant mistakes. ${ }^{17}$ One insurer with surplus assets of $£ 696$ million at the end of 2004 had a change in its model in 2005 that increased its surplus by $£ 251$ million, with a further $£ 35$ million arising from changes in the way policies were grouped into "model points". Other examples were an insurer having a $£ 90$ million increase in surplus from correcting an error in the tax calculation, elsewhere a reduction of $£ 156$ million resulting from improvements to the coding of an insurer's model. While it is reasonable to expect that the number of errors will diminish over time, changes are still taking place that can be disconcerting. For example, one insurer's surplus, which was $£ 1346$ million at the end of 2007, suffered a reduction of $£ 341$ million in 2008 as a result of "modelling and methodology changes".

The second new requirement in 2004 was a stress test for these life insurers, leading to a capital requirement called the "risk capital margin". Briefly, this involved examining the effects of a 20 per cent change in the value of equities, a 12.5 per cent change in value of property and a 17.5 per cent change in long-term interest rates (e.g. from 5 per cent to 4.125 per cent). An increase in the corporate bond spread was to be assumed. In addition, one element of insurance risk was tested: a change of 32.5 per cent in the persistency rate (i.e. the rate at which policies lapse or are surrendered, for example from 5 per cent per annum to either 3.375 per cent or 6.625 per cent). The risk capital margin was the amount needed to cover the most adverse scenario. This stress test is intended to be consistent with what an average diversified and wellmanaged insurer would require to hold in order to have a 99.5 per cent probability that, in a year's time, its assets were at least equal to its liabilities. ${ }^{18}$

The errors in insurers' models mentioned above will also have impacted on their stress tests and we should not therefore regard the tests as 100 per cent accurate.

\footnotetext{
${ }^{15}$ Purchase et al. (1989) used the stochastic model developed by Wilkie (1986) and a ruin probability of 1 per cent.

${ }^{16}$ O'Brien (2006).

${ }^{17}$ The examples for 2004/2005 are from O'Brien (2009).

18 This reflected modelling work carried out by Watson Wyatt (2004).
} 
Further, in an adverse scenario, an insurer would respond with risk mitigation, taking "management actions" such as changing its investment strategy or rates of bonus (dividends) for policy-holders. However, not all insurers have a dynamic risk model that allows for management actions in their models, ${ }^{19}$ and this means that the effect of a stress test is shown to be more adverse than it would be in reality.

\section{Probabilistic modelling in insurance}

Insurers using probabilistic modelling assess the probability of their financial position being at different levels. KPMG described a number of advantages of probabilistic approaches:

- The results consist of not only outcomes related to specific scenarios, but also the probability distribution of possible outcomes.

- There is flexibility to vary the capital definition.

- The interaction of different risks is considered, combining and refining distinct risk categories.

- There is an improved ability to recognise the effect of reinsurance and hedges, and to enhance internal risk management procedures.

However, there are also disadvantages:

- The capital definitions are more difficult to understand than scenario-based definitions.

- The results are from a range of simulation processes, so an intuitive understanding of a result is difficult (for example, because the reader cannot comprehend the large volume of inputs and feels the result comes from a black box).

- This is a complex approach with demanding data requirements and subjectivity, where required data are not widely available and expensive to implement.

- It is difficult to standardise or codify probabilistic approaches.

Insurers have been using probabilistic modelling increasingly from the 1990s. Their ability to do so has been improved by advances in computing technology and by the way in which actuaries have applied financial economics to insurance problems. Insurers have also found that the modelling has produced new insights into the management of the business, and has helped them identify and manage risks. KPMG's survey showed that even large European insurers were still at early stages of building and using comprehensive models; contrast a more recent report ${ }^{20}$ that indicates insurers having taken significant steps forward.

Probabilistic models can also help insurance regulators. From 2004 onwards the FSA has required U.K. insurers to carry out an Individual Capital Assessment (ICA). ICA reports are intended to identify the risks to which an insurer is exposed, and assess the

\footnotetext{
${ }^{19}$ Liebwein (2006) draws attention to a dynamic model as one that takes account of the change to investment strategy if, for example, solvency worsened.

${ }^{20}$ CEIOPS' Internal Model Expert Group (2009).
} 
Table 1 ICA stresses: Phoenix Life

\begin{tabular}{ll}
\hline Indicator & Stress \\
\hline Equity prices & Fall by $43 \%$ \\
Equity volatility & Increases to $35 \%$ \\
Property prices & Fall by $36 \%$ \\
Property volatility & Increases to $25 \%$ \\
Interest rates: parallel yield curve shift & Fall by 1.4 and rise by 2.5 percentage points \\
Interest rate volatility & Increase by 12 percentage points \\
Inflation & Increase by 2.2 percentage points \\
\hline
\end{tabular}

Source: Phoenix Life et al. (2008).

capital that the directors regard as needed so that the company can continue to operate, with a high degree of confidence in its solvency. This is usually expressed as a 99.5 per cent probability of having assets at least equal to liabilities in a year's time.

The ICA has to consider the full range of the insurer's risks categorised by FSA as market, credit, insurance, liquidity, operational and group risks. In principle, an insurer could assess a probability distribution for each of these risk types, although each presents its own difficulties. For example, operational losses are not easy to model and fat tails are apparent. Selvaggi (2009) ${ }^{21}$ reports on the collection of data on insurance operational losses and the modelling of such losses. For mortality risk, probabilistic forecasts are in their infancy: work is ongoing, ${ }^{22}$ and with concerns that parameters in models may be incorrect. ${ }^{23}$

Insurers need to combine the outcome of considering the various risk types. This aggregation process is complex, especially as the correlations between risks are many and not constant. One possibility is a stochastic approach that uses a simulation model to consider all risks together. ${ }^{24}$ If the insurer can produce an overall probability distribution of its position in a year's time, it could read off the 99.5 per cent VaR (and could also calculate TVaR). However, such an approach is very difficult in practice. In practice, many insurers construct a scenario that is consistent with a 99.5 per cent probability of solvency and use the outcome of that stress test as the 99.5 per cent VaR. This is a stress test with a probability attached, so we regard this as a probabilistic approach. However, as the insurer calculates only one point of the probability distribution, it is unable to assess TVaR. The Swiss Solvency Test is, however, based on TVaR.

An example of the ICA stress tests that Phoenix Life and its sister companies used is shown in Table 1. In addition to those shown, there is a twist in the interest rate curve, an increase in spreads on bonds (also applied to sovereign bonds), and changes in mortality and persistency. In this case, the stresses are more severe than in the calculation of the risk capital margin, and different firms use different indicators and parameters.

\footnotetext{
${ }^{21}$ Selvaggi (2009).

${ }^{22}$ For example, Blake et al. (2008).

23 Richards (2009).

${ }^{24}$ Association of British Insurers (2007).
} 
A major difficulty in probabilistic modelling is establishing the extent to which risks are correlated. This is especially important for diversified insurers, whose capital requirement is lower than otherwise because risks are not fully correlated. Deloitte ${ }^{25}$ indicated possible correlations between risk types. However, in several cases, data were not available to establish correlations with any real confidence: for example, the correlations between market risk and lapse and surrender risks had an indicative range of $0-75$ per cent; the indicative range for the correlation between annuitant mortality and assured life mortality was from -75 per cent to -20 per cent.

If the FSA regards the ICA amount as inadequate, it can require insurers to hold a higher level of capital: this is "Individual Capital Guidance" (ICG). On average, the ICG for life insurers was 114 per cent of the International Association of Insurance Supervisors (ICA). ${ }^{26}$ One of the most common reasons for imposing an ICG was if the FSA was not satisfied about an insurer's assumptions on correlations between risks.

There has been a clear trend to use probabilistic modelling: Gneiting ${ }^{27}$ suggested more generally that we may be witnessing what future generations might refer to as the transition from point prediction to distribution prediction, or probabilistic forecasting. However, banks and life insurers (and their regulators) have continued to use, and to develop, stress tests, so that they can use both tools.

\section{Solvency II}

Solvency II is the new solvency regime for EU insurers, the directive having been approved by the European Parliament in May 2009. The capital requirements for insurers are a Minimum Capital Requirement and a Solvency Capital Requirement (SCR). The latter will have a standard formula, derived so as to be consistent with a VaR calculation with a confidence level of 99.5 per cent over a one year period. In other words, what capital is needed so as to be 99.5 per cent certain that, in a year, the insurer's assets will at least equal its liabilities? Backing up these capital requirements is a requirement for insurers to carry out an "own risk and solvency assessment" (ORSA), in which an insurer describes the way it identifies and manages its risks, sets out its solvency needs in accordance with its risks and reports on its compliance with capital requirements.

The SCR formula will use stress tests: for example, in the Quantitative Impact Study 4, an assumption of a 32 per cent fall of equity prices was used.

The directive allows an insurer to calculate the SCR not using the standard formula but instead using an internal model, if approved by the regulator. The model would use a probabilistic approach to calculate the 99.5 per cent VaR. This is, in principle, appropriate, as the model can reflect the firm's specific circumstances and risks, which may differ from the assumptions made in designing the SCR formula. Consistent with IAIS standards, ${ }^{28}$ an internal model has to meet a number of requirements in order that the regulator can approve its use. In particular, the methods used to calculate the

\footnotetext{
${ }^{25}$ Deloitte (2005).

${ }^{26}$ Financial Services Authority (2007).

27 Gneiting (2008).

${ }^{28}$ International Association of Insurance Supervisors (2008a).
} 
Table 2 Stress tests and stresses in 2008

\begin{tabular}{lcclc}
\hline Indicator & $\begin{array}{c}\text { Stress test } \\
\text { movement in } \\
\text { calculating risk } \\
\text { capital margin }(\%)^{\mathrm{a}}\end{array}$ & $\begin{array}{c}\text { 1980s } \mathrm{s} \\
\text { scenario }^{\mathrm{b}}\end{array}$ & Measure & $\begin{array}{c}\text { Change in measure } \\
\text { in 2008 }\end{array}$ \\
\hline Share prices & 20 & $-20 \%$ & FT-All Share Index & $-32.8 \%$ \\
Property prices & 12.5 & $-15 \%$ & IPD U.K. Index & $-26.3 \%$ \\
Interest rates & 17.5 & \pm 50 basis points & 15 year gilt yield & $-17.6 \%$ or -79 basis points
\end{tabular}

${ }^{\text {a }}$ There are also changes in credit spreads and persistency.

${ }^{\mathrm{b}}$ There are also changes in credit spreads.

Source: Author's calculations; Financial Services Authority (2009a, b).

probability distribution forecast have to be based on adequate, applicable and relevant actuarial and statistical techniques; they should be based on current and credible information and realistic assumptions; the data used for the model have to be accurate, complete and appropriate; insurers may take account of further management actions that they would reasonably expect to use.

Solvency II is not limited to a probabilistic approach and encompasses a range of other requirements, including stress tests, risk management processes, public disclosure and supervisory monitoring. However, concern was expressed that the focus on stochastic simulation could adversely affect market stability. ${ }^{29}$

\section{The crisis-Stress tests}

How did stress tests perform in the global financial crisis? Particular attention has been paid to banks. De Larosière et al. ${ }^{30}$ criticised their stress testing as often based on mild or even wrong assumptions, adding "Clearly, no bank expected a total freezing of the inter-bank and commercial paper markets". In the U.K., the FSA found a number of problems. ${ }^{31}$ Many banks admitted their tests were not fit for purpose, as they were not designed for the type of extreme market events of 2007/2008. Haldane explains the institutional failings: banks did not have incentives to carry out challenging stress tests; stress testing was "regulatory camouflage". 32

How have stress tests for insurers performed in the crisis? The financial tests in the U.K.'s "risk capital margin" for major life insurers writing participating business are shown in Table 2; we note they were less demanding in 2008 than actual events and comment on this later.

The FSA has, as one of its responses to the crisis, asked insurers to carry out additional stress testing. It published an economic scenario based on the U.K. economy in the 1980s ("1980s V scenario") and asked insurers to carry out a stress test

\footnotetext{
${ }^{29}$ Bäte et al. (2006).

${ }^{30}$ De Larosière et al. (2009).

${ }^{31}$ Financial Services Authority (2008c).

${ }^{32}$ Haldane (2009).
} 
assuming this applied in 2009. This is also shown in Table 2. Moves to review stress tests have been made elsewhere: in Germany, the stress change in equity prices has been reduced if equities are relatively low, which may be interpreted as a sign of the flexibility that stress tests offer. The Committee of European Insurance and Occupational Pensions Supervisors (CEIOPS) has also announced an EU-wide stress test for the insurance sector in December 2009. ${ }^{33}$

\section{The crisis-Probabilistic modelling}

The crisis also leads us to ask whether probabilistic models contain probabilities that mean the models are not fit for purpose.

In banking, de Larosière et al. ${ }^{34}$ found that European banks' model-based risk assessments underestimated their exposure to tail risks: VaR used risk assessments that were flawed. FSA, ${ }^{35}$ writing about banks, referred to "mis-placed reliance on sophisticated maths". It is concerned that the very complexity of the mathematics made it increasingly difficult for bank management to assess and exercise judgement regarding risks, and relying on $\mathrm{VaR}$ may have meant that other indicators of increasing risks were overlooked.

In insurance, FSA wrote about Solvency II in 2008: “... the 99.5 per cent VaR confidence level over one year is the common requirement to be met through regulatory capital. This level of safety represents one of the core components of the new regime". ${ }^{36}$ However, the concerns about VaR that de Larosière et al. and FSA have, as referred to in the previous paragraph, suggested that the ability of an insurer (or regulator) to determine robustly what capital level is consistent with 99.5 per cent security is open to question.

The crisis has stimulated questions about current practice and considering what might be feasible going forward. The International Actuarial Association ${ }^{37}$ has criticised the focus on VaR, with concerns that we need to use fat-tailed non-normal distributions to avoid systematically underestimating real risk exposures. Haldane ${ }^{38}$ refers to "disaster myopia": the probabilities of very adverse outcomes are frequently under-estimated. He also highlights "network externalities": spillovers from the Lehman Brothers' failure illustrate how the effects of problems can spread unexpectedly. This is an indication that we ought to expect fat tails in distributions, although models typically assume normality.

Difficulties in modelling are also apparent in the insurance sector. When U.K. life insurers carry out the "realistic valuation", they use a model that is intended to produce market-consistent valuations of options and guarantees, and they use an economic scenario generator to help achieve this. The model contains assumptions

\footnotetext{
33 CEIOPS (2009b).

${ }^{34}$ de Larosière et al. (2009).

${ }^{35}$ Financial Services Authority (2009a).

${ }^{36}$ Financial Services Authority (2008a).

${ }^{37}$ International Actuarial Association (2009).

${ }^{38}$ Haldane (2009).
} 
Table 3 Correlations between assumed investment returns between equities and other asset classes

\begin{tabular}{lcccc}
\hline & Government bonds & Corporate bonds & Bonds $^{\mathrm{a}}$ & Property $^{\circ}$ \\
\hline Minimum & 0.06 & 0.20 & -0.52 & 0.07 \\
Maximum & 0.30 & 0.54 & 0.47 & 0.70 \\
Mean & 0.17 & 0.34 & -0.04 & 0.26 \\
Standard deviation & 0.08 & 0.12 & 0.33 & 0.18 \\
No. of observations & 8 & 6 & 13 & 20 \\
\hline
\end{tabular}

${ }^{\mathrm{a}}$ Where not specified as regards government or corporate bonds.

Source: Author's calculations from U.K. insurers' regulatory returns to FSA at end-2008.

regarding correlations between the assumed returns on different asset classes; these are reported in the insurers' regulatory returns. Table 3 shows the assumed correlations between equities and other asset classes. There are some significant differences between insurers. For example, some firms assume the correlation between bond returns and equity returns is negative, whereas others assume it is positive. The correlations reported are not specified exactly (e.g. do they apply in the short or long term), but this will not explain all of the differences. This exemplifies the difficulties in aiming for robust modelling.

\section{Three gaps in probabilistic modelling}

The global financial crisis has highlighted deficiencies in insurers' probabilistic modelling. We identify three types of gap when comparing models with what is theoretically required.

The first gap is where an insurer's model does not conform to best practice. In particular, we highlight AIG, where the models did not attempt to measure the risk of future calls of collateral or write-downs, leaving the firm exposed to potentially large collateral because it had not hedged its risks. ${ }^{39}$ Examples can be seen from U.K. life insurers, where some do not incorporate management actions in their modelling. Other issues are more routine: for example, one insurer has a model that does not distinguish between government and corporate bonds: while these classes are typically highly correlated, the model would be exposed in 2008 when corporate bond spreads widened and led to severe losses. The continued correction of errors also demonstrates the need for improvements. Some issues can be addressed by better documentation of models, which can be inadequate. ${ }^{40}$

Second is the gap that can be rectified by an improvement in best practice. For example, Brooks et al. ${ }^{41}$ set out a view of what would be good practice modelling by 2012 when Solvency II is in place, describing steps needed to achieve that, for example by choosing appropriate approaches to co-dependencies between risk factors.

There is also the potential for further work on alternatives to the normal distribution: we know there are fat tails. However, the mileage to be gained may be

\footnotetext{
${ }^{39}$ Mollenkamp et al. (2008).

${ }^{40}$ Board for Actuarial Standards (2009).

${ }^{41}$ Brooks et al. (2009).
} 
quite modest. Which fat-tail distribution should we use and with what parameters? Frankland et al $^{42}$ focused on modelling the market risk of equities at a 99.5 per cent confidence level. Fitting curves with different distributions and parameters produced different answers, leaving us unsure as to whether a one in 200 event corresponded to a market drop of 35 per cent or 75 per cent.

The third gap is arguably the most important. This is the extent that any model, however good, should not be viewed as a reliable indicator of the potential future financial condition of the insurer. A major lesson from the financial crisis is that the unexpected can happen. Some said that the events of autumn 2007 represented 25 -sigma events, that is 25 standard deviations from what was expected. However, a 25 -sigma event is extremely unlikely; ${ }^{43}$ an alternative interpretation is that the models used were misleading.

$\mathrm{Kay}^{44}$ was sceptical about trying to fix the problems of modelling economic and social systems with ever more sophisticated models. There is always the risk of off-model events that no model-builder could reasonably anticipate. Kay advocated seeing the models as metaphors, rather than attempts directly to reflect reality: "their results were thus neither true nor false but could be used in context to illuminate the processes involved, and suggest questions to be addressed thus assisting the good human judgement that in the end was what counted". This third gap therefore reflects the role of "uncertainty": however hard we try, we will not know precisely what the probabilities really are.

\section{Three suggested lessons from the crisis for regulators}

CEIOPS ${ }^{45}$ has indicated a need to refine the existing Solvency II calibrations. The author's view is that this is right and proper: when we have new information about the distribution of risks, we should take it into account. Does this mean that the existing SCR calibrations represent a survival ratio of slightly under 99.5 per cent? Perhaps. However, the author cautions against paying too much attention to small differences in extreme percentiles. He suggests that the first lesson for regulators is that there is the third gap in probabilistic approaches that cannot be filled.

Regulators may accept the difficulties in sophisticated mathematics, but there is a danger that they are still too willing to rely on modelled figures that appear objective. If the alternative is that the regulator has to exercise judgments regarding the appropriateness of the insurer's governance structure, and the capability of its senior management, one can understand regulators' preference for models. But, while probabilistic approaches have some contribution to make in solvency assessment, it is important that regulators understand their limitations.

The author likewise suggests that regulators need to adopt a critical stance in assessing insurers' internal models. A model may apply apparently relevant techniques, it may be calibrated and back-tested, but that does not necessarily mean

\footnotetext{
${ }^{42}$ Frankland et al. (2008).

${ }^{43}$ Dowd et al. (2008). They suggest a comparison: the probability of a 25 -sigma event is lower than the probability of winning the U.K. national lottery 21 times in a row.

${ }^{44}$ Kay (2009).

${ }^{45}$ CEIOPS (2009a).
} 
it produces sound financial projections. If a model produces capital requirements that are relatively low, regulators must clearly challenge it.

The second lesson suggested is that regulators need to acknowledge that setting minimum capital levels has limitations, and must pay careful attention to insurers' risk management and governance. As a former Chairman of the FSA said: “... no amount of capital is enough if the management in charge of it is incompetent, and the control systems are fatally flawed". ${ }^{46}$ Hence, the management of and processes in a firm are critical. CEIOPS (2009a) drew attention to the need to strengthen governance, risk management and internal controls in the insurance sector, as in the financial sector at large. These issues are judgemental. However, de Larosière et al. commented, "Future rules will have to be better complemented by more reliance on judgement, instead of being exclusively based on internal risk models." 47

Related to this, regulators must consider insurers' incentive systems. Since insurance is a long-term business, there is a potential problem if remuneration is geared to current measures of success rather than performance over the long term.

The third suggested lesson is the role of stress tests. Financial services regulators have recognised the importance of stress tests and have investigated the financial position of banks in both the U.S. and Europe in the event of specified stresses. FSA ${ }^{48}$ has suggested that the use of $\mathrm{VaR}$ models needs to be buttressed by the application of stress test techniques that consider the impacts of extreme movements. More specifically for insurance, CEIOPS ${ }^{49}$ has highlighted that the SCR assessment of solvency needs to be complemented by a rigorous stress testing requirement under the second pillar. IAIS has acknowledged that stress tests are one of the tools used by insurance regulators. ${ }^{50}$

Regulators' ideas around stress tests have also been developing. The FSA ${ }^{51}$ proposed that firms - both banks and insurers - carry out "reverse-stress testing". This means identifying scenarios that would lead the business to fail. This goes beyond considering, for example, what change in interest rates or share prices would lead the firm to be insolvent; it requires firms to determine what changes in market conditions would make the insurer's business model unsustainable.

As problems in stress tests have already been identified, it is important to address them, which appears feasible, at least to some extent. Haldane ${ }^{52}$ sets out a five-point plan for improvement, involving choosing stresses in a better way and evaluating those choices, assessing second-round effects of stresses, translating the results into firms' liquidity and capital planning, and providing transparency to regulators and markets. One practical suggestion from Aragonés et al. ${ }^{53}$ is that firms have a stress test committee, including senior management representatives, making them accountable for the scenario design process: having a variety of perspectives can be very valuable. Further,

\footnotetext{
${ }^{46}$ Davies (2001).

47 de Larosière et al. (2009).

${ }^{48}$ Financial Services Authority (2009a).

${ }^{49}$ CEIOPS (2009a).

${ }^{50}$ IAIS (2009).

${ }^{51}$ Financial Services Authority (2008b).

52 Haldane (2009).

${ }^{53}$ Aragonés et al. (2008).
} 
we are conscious that stress tests may use an insurer's model, where effort needs to be made to correct any errors (which should be simpler than for a VaR model, which incorporates probabilities).

We contribute to the debate by adding three further suggestions for stress testing. First, it would help European insurers if the requirements arising from Solvency II and those from a new insurance accounting standard from IASB were co-ordinated and, to the extent appropriate, consistent. Hence, if IASB seeks disclosure of sensitivities to changes in interest rates, share prices and claim rates, one of the steps regulators can take is to require disclosure of stresses (more extreme than sensitivities in the accounts) of the same parameters, one by one, in addition to a scenario that combines different events. Co-ordinating accounting and solvency requirements should make implementation easier and help transparency.

Second, some of the stress tests required by regulators should reflect actual historical events. If a test is to reflect a one in-200 year event, it is reasonable to ask how an insurer would be affected by the 1974 oil crisis or the 1987 stock market crash, for example. In this context, the stress tests used by FSA (Table 2) appear quite weak. CEIOPS has a new test based on market movements from September 2008 to September $2009^{54}$ but it is not clear that this is sufficiently challenging if 99.5 per cent security is the aim.

Third, stress testing needs to incorporate backward-looking checking. Consider an insurer at the end of 2007 with its sensitivities at that time to, for example, share prices and economic growth. If it applied actual 2008 events (e.g. stock market prices falling by 32.8 per cent and so on) to its stated sensitivities, to what extent would its projected financial position at the end of 2008 have differed from reality - for example, because the shares held by the firm differed from the index, or because the actual sensitivity of credit losses to an economic downturn was more than the sensitivity used at end-2007? The sensitivities may need revision in the light of experience.

The merits of stress tests should be apparent to firms. FSA ${ }^{55}$ indicated that they help insurers to test the robustness of their financial position and business plans, and act as a sense-check on the assumptions in models. They can simulate the correlations between individual stresses, and provide an effective way to communicate an insurer's main exposures to senior managers. In addition to being used for risk and capital management, they can be valuable in helping an insurer develop its strategy. ${ }^{56}$ However, it is clear that stress tests need to be better done in the future.

Stress tests are part of the SCR formula being developed for Solvency II. There are inevitably doubts over whether the outcome is consistent with the 99.5 per cent figure in the directive. Rather, we accept that absolute precision is not achievable. We should appreciate that stress tests do not contain ruin probabilities, but whereas VaR does so, those probabilities can be deceptive. We should recognise that stress tests are a coherent risk measure, whereas $\mathrm{VaR}$ is not. We can have a plan for improving stress testing, and while insurers can improve their probabilistic modelling, there will remain the third gap that is our inability to assess probabilities. We can understand what

\footnotetext{
${ }^{54}$ CEIOPS (2009b).

${ }^{55}$ Financial Services Authority (2008b).

56 Swiss Re (2009).
} 
a stress test means for what adversity an insurer can withstand, whereas VaR lacks transparency and does not easily help our understanding. Stress tests are also a relatively simple way to communicate risks, which should simplify the appreciation of risks by the board and senior management, and help promote risk management within insurers, which is a desirable goal for insurance regulators.

The global financial crisis was an unforeseen event that has reduced our confidence in probabilistic modelling. However, the stresses of the crisis have alerted us to the important role that stress tests can play in the future regulatory regime for insurers.

\section{References}

Aragonés, J., Blanco, C. and Dowd, K. (2008) Stress Tests, Market Risk Measures and Extremes: Bringing Stress Tests to the Forefront of Market Risk Management: Stress Testing for Financial Institutions, London: Risk Books.

Association of British Insurers (2007) 'Individual Capital Assessment. A Guide to the ICA Process for Insurers'.www.abi.org.uk/Information/Codes_and_Guidance_Notes/43773.pdf.

Bank for International Settlement (1994) 'Public Disclosure of Market and Credit Risks by Financial Intermediaries.' www.riskinstitute.ch/138220.htm.

Basel Committee on Banking Supervision (1996) 'Amendment to the Capital Accord to Incorporate Market Risks.' www.bis.org/publ/bcbs24.pdf.

Bäte, O., von Plato, P. and Thallinger, G. (2006) 'Stochastic modelling - Boon or bane for insurance industry capital regulation?', The Geneva Papers on Risk and Insurance-Issues and Practice 31(1): $57-82$.

Blake, D., Dowd, K. and Cairns, A. (2008) 'Longevity risk and the grim reaper's toxic tail: The survivor fan charts', Insurance: Mathematics and Economics 42: 1062-1068.

Board for Actuarial Standards (2009) 'Exposure Draft: Modelling'. www.frc.org.uk/images/uploaded/ documents/Modelling\%20ED\%20Final.pdf. (May 2009).

Brooks, D., Care, R.J., Chaplin, M.B., Kaufman, A.M., Morgan, K.A., Roberts, D.N., Skinner, J.M.E., Huntington-Thresher, D.J.K., Tuley, P.J. and Wong, D.L. (2009) Actuarial aspects of internal models for Solvency II, paper presented to the Institute of Actuaries, London, February.

CEIOPS (2009a) 'Lessons Learned from the Crisis (Solvency II and beyond)'. www.ceiops.eu/media/files/ publications/reports/CEIOPS-SEC-107-08-Lessons-learned-from-the-crisis-SII-and-beyond.pdf.

CEIOPS (2009b) 'CEIOPS members will run EU-wide stress test in the insurance sector in December 2009', Press release, www.ceiops.eu/media/docman/public_files/pressreleases/Press-Release-Stress-testinsurance-sector-2009.pdf.

CEIOPS' Internal Model Expert Group (2009) 'Stock-Taking Report on the Use of Internal Models in Insurance'. www.ceiops.eu/media/files/publications/reports/Stock-taking-report-on-the-use-ofInternal-Models-in-Insurance.pdf.

Davies, H. (2001) Speech: 'Management skills and competencies in a rapidly changing financial environment', Egon Zehnder International Insurance symposium, Munich, from www.fsa.gov.uk/Pages/ Library/Communication/Speeches/2001/sp78.shtml, accessed 14 July 2009.

De Larosière, J., Balcelowicz, L., Issing, O., Massera, R. and McCarthy, C. (2009) The High-Level Group of Financial Supervision in the EU, report, Brussels.

Deloitte (2005) Report for the Association of British Insurers on Key Correlation Assumptions in ICA for Life Offices, London: Deloitte.

Doff, R. (2008) 'A critical analysis of the Solvency II proposal', Geneva Papers on Risk and InsuranceIssues and Practice 33(2): 193-206.

Dowd, K. and Blake, D. (2006) 'After VaR: The theory, estimation, and insurance applications of quantilebased risk measures', Journal of Risk and Insurance 73: 193-229.

Dowd, K., Cotter, J., Humphrey, C. and Woods, M. (2008) 'How unlucky is 25 sigma?', Journal of Portfolio Management 34(4): 76-80.

Fender, I. and Gibson, M.S. (2001) 'Stress testing in practice: a survey of 43 major financial institutions', BIS Quarterly Review (June): 58-62. 
Financial Services Authority (2007) 'Insurance sector briefing. ICAS - Lessons learned and looking ahead to Solvency 2,' London: Financial Services Authority.

Financial Services Authority (2008a) Insurance Risk Management: The Path to Solvency II, Discussion paper 08/4. Financial Services Authority (2008b) Insurance Sector Briefing. Risk and Capital Management Update, London: Financial Services Authority.

Financial Services Authority (2008c) Stress and Scenario Testing, Consultation paper 08/24.

Financial Services Authority (2009a) 'The Turner Review. A Regulatory Response to the Global Banking Crisis', London: Financial Services Authority.

Financial Services Authority (2009b) 'Use of Stress Testing in the Insurance Sector', www.fsa.gov.uk/pages/ Library/Communication/Statements/2009/ins_stresstst.shtml.

Frankland, R., Smith, A.D., Wilkins, T., Varnell, E., Holtham, A., Biffis, E., Eshun, S. and Dullaway, D. (2008) Modelling extreme events, paper presented to the Institute of Actuaries, London, November.

Gneiting, T. (2008) 'Probabilistic forecasting', Journal of Royal Statistical Society, A series 1710(2): 31-32.

Haldane, A.G. (2009) 'Why Banks Failed the Stress Test', from www.bankofengland.co.uk/publications/ speeches/2009/speech374.pdf, accessed 14 July 2009.

International Actuarial Association (2009) 'Dealing with Predictable Irrationality - Actuarial Ideas to Strengthen Global Financial Risk Management, from www.actuaries.org/CTTEES_TFRISKCRISIS/ Documents/IAA_Financial_Risk_Management_EN.pdf

International Association of Insurance Supervisors (2008a) Guidance Paper on the Use of Internal Models for Regulatory Capital Purposes. www.iaisweb.org/_temp/15_Guidance_paper_No_2_2_6_on_the_use_of_ Internal_Models_for_regulatory_capital_purposes.pdf.

International Association of Insurance Supervisors (2009) Issues Paper on Group-Wide Solvency Assessment and Supervision.www.iaisweb.org/_temp/Issues_paper_on_group-_wide_solvency_assessment_and_supervision .pdf.

Kay, J. (2009) 'Discussion: 'Financial models - Key tools for risk analysis or the vector of global financial collapse?', at The Royal Society, 10 June, from www.foundation.org.uk/events/pdf/20090610_Summary .pdf, accessed 14 July 2009.

KPMG (2002) 'Study into the Methodologies to Assess the Overall Financial Position of an Insurance Undertaking from the Perspective of Prudential Supervision', Brussels: European Commission, also at www.ec.europa.eu/internal_market/insurance/docs/solvency/solvency2-study-kpmg_en.pdf.

Linsmeier, T.J. and Pearson, N.D. (1997) 'Quantitative disclosures of market risk in the SEC release', Accounting Horizons 11: 107-135.

Liebwein, P. (2006) 'Risk models for capital adequacy: Applications in the context of solvency II and beyond', The Geneva Papers on Risk and Insurance 31(3): 529-550.

Mollenkamp, C., Mg, S., Plevin, L. and Smith, R. (2008) 'Faulty computer models helped sink giant AIG', The Wall Street Journal Europe 26(194): 1 and 3 (3 November).

O'Brien, C. (2006) 'Modernizing insurance solvency regulation: Evidence from the UK', Journal of Insurance Regulation 25: 41-60.

O'Brien, C. (2009) 'Valuation of life insurance liabilities on a market-consistent basis: experience from the United Kingdom', Actuarial Practice Forum: January.

Phoenix Life Limited, Scottish Mutual Assurance Limited and Scottish Provident Limited (2009) Joint second supplementary report by the actuarial function holders of Phoenix Life Limited, Scottish Mutual Assurance Limited and Scottish Provident Limited.

Purchase, D.E., Fine, A.E.M., Headdon, C.P., Hewitson, T.W., Johnson, C.M., Lumsden, I.C., Maple, M.H., O'Keeffe, Pook, P.J. and Robinson, D.G. (1989) 'Reflections on resilience: some considerations of mismatching tests, with particular reference to non-linked long-term insurance liabilities', Journal of the Institute of Actuaries 116: 347-440.

Rebonato, R. (2007) Plight of the Fortune Tellers, Princeton and Oxford: Princeton University Press.

Richards, S. (2009) 'Investigating parameter risk for Solvency II and ICAS', Life \& Pensions (June): 36-40. Selvaggi, M. (2009) Analysing Operational Losses in Insurance, Association of British Insurers research paper 16. Swiss Re (2009) Scenario analysis in insurance, Sigma 1/2009.

Taleb, N.N. (2007) The Black Swan, London: Allen Lane.

Watson W. and Financial Service Authority (2004) 'Calibration of the enhanced capital requirement for with-profit life insurers. www.fsa.gov.uk/pubs/policy/04_16/ww_report.pdf

Wilkie, D. (1986) 'A stochastic model for actuarial use', Transactions of the Faculty of Actuaries 39: 341-382. 
Woods, M., Dowd, K. and Humphrey, C. (2008) 'The value of risk reporting: A critical analysis of value-atrisk disclosures in the banking sector', International Journal Financial Services Management 3: 45-63.

\begin{abstract}
About the Author
Christopher O'Brien is Director of the Centre for Risk and Insurance Studies at Nottingham University Business School. He was previously Chief Actuary for a U.K. life insurer. His research interests include the management and regulation of insurance compaines, with specific reference to actuarial and risk management, pensions, risk management more generally, and statistical societies. He is a Fellow of the Institute of Actuaries and speaks at a number of actuarial and industry conferences.
\end{abstract}

